\title{
Comparison of a Fistulectomy and a Fistulotomy with Marsupialization in the Management of a Simple Anal Fistula: A Randomized, Controlled Pilot Trial
}

\author{
Do Sun Kim
}

Department of Surgery, Daehang Hospital, Seoul, Korea

See Article on Page 78-82

The ultimate purpose of surgical treatment for an anal fistula is the eradication of sepsis while maintaining continence. To achieve these goals, it is essential to identify the internal opening, as well as the relationship between the fistula tract and the sphincters, before or at the time of surgery. When the internal opening is not identified or is misdiagnosed, recurrence and unnecessary sphincter injury may be the result. Accurate diagnosis of the type of fistula is also important to determine an appropriate surgical treatment. A simple way of differentiating a simple fistula from a complex fistula is palpation of the tract. If the tract is palpable from the external opening to the anal verge, it is safe to regard the fistula as a simple type.

Various surgical treatments, including a fistulotomy, a fistulectomy, a seton and more complex sphincter-preserving procedures, are currently used depending on the type of fistula and the patient's continence. Recently, newer sphincter-preserving treatments, such as fibrin glue injection and fistula plug insertions, have been introduced. However, the postoperative healing rates are unpredictable and sometimes below our expectation. In the case of the ligation of intersphincteric fistula track (LIFT), the procedure is simple and shows results comparable to those of advancement flaps. No studies have been done comparing LIFT with other conventional treatments, and some questions as to whether it is as effective and technically feasible for complicated-course suprasphincteric fistulae or fistulae remain.

Correspondence to: Do Sun Kim

Department of Surgery, Daehang Hospital, 481-10 Bangbae 3-dong,

Seocho-gu, Seoul 137-820, Korea

Tel: +82-2-6388-8114, Fax: +82-2-6388-8115

E-mail:dskim1@daehang.com

(c) 2012 The Korean Society of Coloproctology

This is an open-access article distributed under the terms of the Creative Commons Attribution NonCommercial License (http://creativecommons.org/licenses/by-nc/3.0) which permits unrestricted noncommercial use, distribution, and reproduction in any medium, provided the original work is properly cited.
Therefore, the fistulotomy is regarded as the standard treatment for simple anal fistulae and is the most widely-performed procedure. Although whether to perform a fistulotomy or a fistulectomy may be controversial, the fistulotomy is thought to be preferable because healing times are significantly shorter whereas recurrence rates are comparable.

Compared with the fistulotomy, the fistulectomy is slightly more demanding, especially when the tract has ill-defined walls, because more damage is caused to the tissues surrounding the fistula tracts. A randomized controlled study comparing the fistulectomy with the fistulotomy revealed more sphincter defects in the fistulectomy group [1]. The fistulectomy has a potential advantage over the fistulotomy only when the fistula tract has not been explored via probing.

Marsupialization after anal fistula surgery is postulated to leave less raw unepithelialized tissue in the fistulotomy wound, thereby resulting in less postoperative blood loss and faster wound healing $[2,3]$. However, this added procedure cannot prevent postoperative deformity and showed no improved functional outcome. Marsupialization is not regarded as an essential procedure even though it can facilitate faster wound healing. Therefore, whether to implement marsupialization over a fistulotomy depends on the surgeon's preference. In spite of the limitations of sphincter division, a fistulotomy with or without marsupialization is considered to be a very effective and safe procedure. Particularly in low, simple-type fistulae, the fistulotomy is the most widely-performed procedure.

\section{REFERENCES}

1. Belmonte Montes C, Ruiz Galindo GH, Montes Villalobos JL, Decanini Teran C. Fistulotomy vs fistulectomy. Ultrasonographic evaluation of lesion of the anal sphincter function. Rev Gastroenterol Mex 1999;64:167-70.

2. Pescatori M, Ayabaca SM, Cafaro D, Iannello A, Magrini S. Marsupialization of fistulotomy and fistulectomy wounds improves 


\section{Coloproctology Do sun Kim}

healing and decreases bleeding: a randomized controlled trial. Colorectal Dis 2006;8:11-4.

3. Ho YH, Tan M, Leong AF, Seow-Choen F. Marsupialization of fistulotomy wounds improves healing: a randomized controlled trial. Br J Surg 1998;85:105-7. 